Article

\title{
2-O-Acyl-3-O-(1-acyloxyalkyl) Prodrugs of 5,6-Isopropylidene-L-Ascorbic Acid and L-Ascorbic Acid: Antioxidant Activity and Ability to Permeate Silicone Membranes
}

\author{
Nikki A. Thiele, Jennifer McGowan and Kenneth B. Sloan * \\ Department of Medicinal Chemistry, University of Florida, P.O. Box 100485, Gainesville, FL 32610, USA; \\ nthiele@ufl.edu (N.A.T.); jmm381@case.edu (J.M.) \\ * Correspondence: sloan@cop.ufl.edu; Tel.: +1-352-256-5287
}

Academic Editor: Yvonne Perrie

Received: 25 April 2016; Accepted: 7 July 2016; Published: 18 July 2016

\begin{abstract}
O-Acyl-3-O-(1-acyloxyalkyl) prodrug derivatives, 15, of 5,6-isopropylidene-L-ascorbic acid, VCA, and L-ascorbic acid, VC, have been characterized by measuring (1) their solubilities in water $\left(\mathrm{S}_{\mathrm{AQ}}\right)$ and in 1-octanol $\left(\mathrm{S}_{\mathrm{OCT}}\right)$; (2) the ability of one member of the homologous series, 15a, to diffuse through a silicone membrane from its application in propylene glycol:water (PG:AQ), 30:70; (3) the ability of another member of the series, 15e, to express cellular antioxidant activity (CAA) in $\mathrm{HaCaT}$ cells; and (4) the ability of $\mathbf{1 5 e}$ to support cell viability in $\mathrm{HaCaT}$ cells. All of the prodrugs were more soluble in 1-octanol than VC or VCA were. 15a, which exhibited a good balance between $\mathrm{S}_{\mathrm{OCT}}$ and $\mathrm{S}_{\mathrm{AQ}}$, was found to deliver approximately 15 times more 15a than VCA delivered VCA through a silicone membrane from PG:AQ, 30:70. Under those conditions, no VC permeated the membrane. 15e, which hydrolyzed to release acetaldehyde as a byproduct instead of the toxin formaldehyde, exhibited approximately 30 times the antioxidant activity of VC in CaHaT cells and supported cell viability up to $900 \mu \mathrm{M}$ in $\mathrm{HaCaT}$ cells.
\end{abstract}

Keywords: vitamin C; L-ascorbic acid; prodrugs; topical delivery; solubilities; cellular antioxidant activity; cytotoxicity; soft alkyl

\section{Introduction}

Vitamin C (L-ascorbic acid, VC, 1, Figure 1) is an antioxidant which is frequently used in cosmetic formulations [1]. Not only can VC stabilize the formulation against oxidative degradation, but it can also partition into the skin and serve as an antioxidant there. Unfortunately, VC is so easily oxidized in cosmetic formulations, especially if the formulation is exposed to air and/or light, that its concentration in those formulations is rapidly depleted, leaving the remaining components unprotected from further oxidation [1]. The depletion of VC in the formulation also means that there is little intact VC available to partition into the skin and protect the skin from oxidative processes [2]. In addition to its rapid depletion in cosmetic formulations, the physicochemical properties of $\mathbf{V C}$ are not suitable for achieving sufficient topical delivery for it to be effective. VC is a very polar, hydrophilic molecule. It contains a total of four $\mathrm{OH}$ groups, two of which are acidic; hence $\mathrm{VC}$ is significantly ionized at physiological $\mathrm{pH}$. The effect of the four $\mathrm{OH}$ groups is that the $\log$ partition coefficient $\left(\log \mathrm{K}_{\mathrm{OCT}} \mathrm{AQ}\right)$ of $\mathrm{VC}$ is -1.69 , where OCT is the lipid 1-octanol and AQ is water [3]. Thus, VC is over 50 times more soluble in AQ than OCT under neutral conditions. VC is not sufficiently lipophilic (lipid soluble) to effectively partition into the lipophilic barrier to delivery in the skin —-the stratum corneum-except under acidic conditions when the $\mathrm{OH}$ groups are not ionized and hence $\mathrm{VC}$ is not as polar [2,4]. 
<smiles>O=C1OC([C@@H](O)CO)C(O)=C1O</smiles><smiles>C[13CH2]C(=O)O[C@@H](CO)[C@H]1OC(=O)C(O)=C1O</smiles>

VC, 1<smiles>O=C1OC([C@H](O)CO)C(O)=C1OP(=O)(O)O</smiles>
9<smiles>CCOC1=C(O)C(=O)OC1[C@H](O)CO</smiles>

10

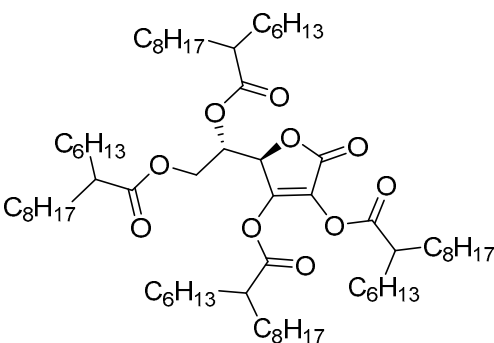

8<smiles>O=C1OC([C@H](O)CO)C(O)=C1OC1O[C@H](O)[C@H](O)[C@H](O)[C@H]1O</smiles>

12

Figure 1. Structures of vitamin C (VC, 1), acylated derivatives (7-9), and alkylated derivatives (10, 12).

VC's antioxidant properties, its instability and its poor physicochemical properties are due to its unique 1-one-2,3-diol-2-ene set of connected functional groups (referred to as the "system" throughout). In the 1-one-2,3-diol-2-ene system the 3-OH group, as a vinylogous carboxylic acid, ionizes first: acidic $\mathrm{pKa}$ of 4.17 [5]. Thus at physiological $\mathrm{pH}, \mathbf{V C}$ is $99.9 \%$ ionized to its highly polar, water soluble 3-monoanion, 2. Loss of one electron from 2 gives a radical 3. Notably, the ionization of the 2-OH group of 3 to form 4 [6] is more facile than is the ionization of the 2-OH group of the 3-monoanion, 2 [5]. This difference is reflected in the acidic pKa values of their 2-OH groups: -0.86 vs. 11.57 for 3 vs. 2. Finally, loss of another electron from 4 gives the diradical 5, which rearranges to inactive dehydroascorbic acid 6 . In the process, VC gives up two protons and two electrons to quench free radicals being formed in a formulation and/or in the skin.

One way to stabilize the 1-one-2,3-diol-2-ene system in VC to premature oxidation and to improve its delivery into the skin is to mask the $3-\mathrm{OH}$ group with chemical derivatives that prevent its ionization at physiological $\mathrm{pH}$ to the very polar 3-monoanion 2 [7]. The 2-OH group is not sufficiently acidic (acidic $\mathrm{pKa}=11.57$ ) at physiological $\mathrm{pH}$ to be significantly ionized as long as the 3-monoanion has not donated an electron to form the radical 3. However, the 2-OH remains a polar functional group that contributes to the poor lipophilicity of VC, so masking it is also desirable. If the masking agents contain lipophilic alkyl groups, these types of masked derivatives of VC have the benefit of increasing the lipid solubility (lipophilicity) of the derivative in addition to preventing ionization of the 3-OH group. Furthermore, these masking agents must be transient and revert to VC either enzymatically or chemically in a predictable manner that is reasonably rapid and complete. This is because both the 3-OH and the 2-OH groups are essential for the expression of the full complement of the antioxidant properties of VC. Such transiently-masked derivatives are called prodrugs and the masking agents are called promoieties.

Numerous transient and non-transient derivatives of VC have been synthesized through the years to stabilize the 1-one-2,3-diol-2-ene system against oxidation and/or to increase the lipophilicity of VC in attempts to make delivery of VC into the skin more effective. Alkylcarbonyl derivatives of the 6-OH group in VC (such as the 6-O-palmitate ester of VC, 7, Figure 1) increase the lipophilicity of VC but do not effectively revert to VC (when applied topically, they are not prodrugs) and do not effectively stabilize the 1-one-2,3-diol-2-ene system against oxidation. This is because the 3-OH can still ionize and donate electrons as outlined above for VC in Figure 2 to give the 6-O-palmitate ester of 6 [1]. Alkylcarbonyl and alkyloxycarbonyl derivatives of all four $\mathrm{OH}$ groups (such as the 2-O-, 3-O-, 5-O-, 6-O- tetra-isopalmitate ester of VC, 8, Figure 1) also increase the lipophilicity and 
do prevent the ionization of the 3-OH, effectively stabilizing the 1-one-2,3-diol-2-ene system against oxidation. Unfortunately, these tetra acyl derivatives are too large and are too lipid soluble to cross the stratum corneum into the skin: they do not exhibit a good balance between lipid and aqueous solubilities [7]. Also, acylation of the acidic 3-OH group essentially gives a vinylogous carboxylic acid anhydride. Anhydrides are very reactive agents and may cause irritation and potential toxicity if they are applied to the skin. In addition, the 3-O-acyl derivatives are likely to be too unstable to formulate, especially for cosmetic application, with the 3-O-acyl groups hydrolyzing first as expected for an anhydride versus the 2-O-ester. Besides the more lipophilic $O$-acyl derivatives, salts of the acyl-like 2-O-phosphate derivative, 9 (Figure 1), have also been marketed. The 2-O-phosphate reverts to $\mathrm{VC}$ by the action of phosphatases. The 2-O-phosphate also stabilizes the 3-OH group to ionization, and hence its subsequent rapid oxidation by formation of the radical 3 (Figure 2), not by masking it but by suppressing its ionization by the introduction of the even more acidic $\mathrm{P}(=\mathrm{O})-\mathrm{OH}$ group (acidic $\mathrm{pKa}=2$ ). However, the phosphate derivative is even more hydrophilic than $\mathbf{V C}$, so it does not improve the delivery of $\mathbf{V C}$ across the skin where increased lipophilicity is required [1].

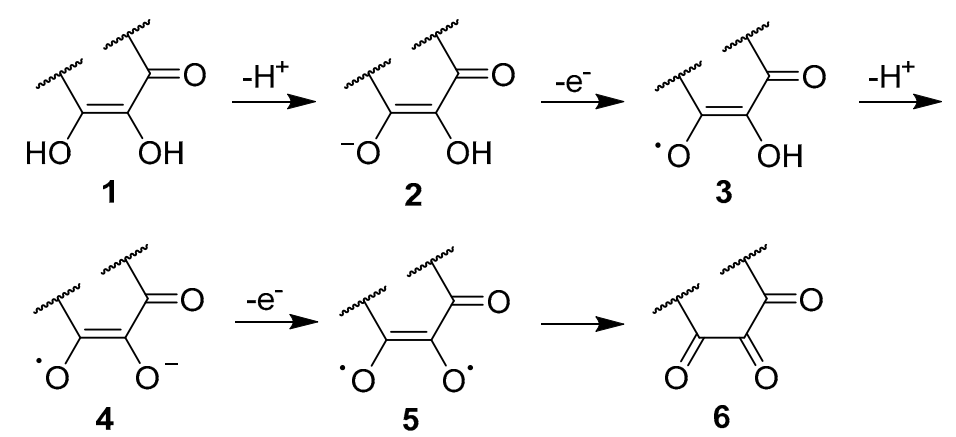

Figure 2. Mechanism for the ionization and oxidation of VC, 1, to inactive dehydroascorbic acid, 6. Partial structures are shown.

A second approach that has been taken to stabilize VC to oxidation and to improve its delivery across the skin by making it more lipophilic is to alkylate only the 3-OH or 2-OH group. An example of this approach is the 3-O-ethyl VC derivative, 10 (Figure 1). The 3-O-ethyl derivative masks the 3-OH, preventing its ionization and the subsequent oxidation of VC. The 3-O-ethyl derivative is also predicted to be more lipophilic than VC because of the added lipophilic ethyl group and hence exhibit improved permeation of the skin [1]. However, it is unlikely to deliver VC because ethers such as 10 can only undergo reversion to VC through a CYP-mediated alpha oxidation of the ethyl group to give an alpha-hydroxyethyl hemiacetal derivative, 11, which can then spontaneously decompose to an aldehyde (acetaldehyde in this case) and VC, $\mathbf{1}$ (Figure 3). Another alkyl derivative is the 2-O-glucoside, 12 (Figure 1). The 2-O-glucoside undergoes reversion to VC by cellular $\alpha$-glucosidase. However, the 2-O-glucoside is even more polar than VC and not more lipophilic because of the addition of four polar $\mathrm{OH}$ groups [1]. Thus, it does not improve the delivery of VC into the skin. Although the 2-O-glucoside does not mask the 3-OH group, it does prevent the second ionization of VC (3 to 4) as shown in Figure 2, which is a very important step in preventing the oxidation of VC to 6.<smiles>CCOC1=C(O)C(=O)C(C)C2CC1C2</smiles>

10

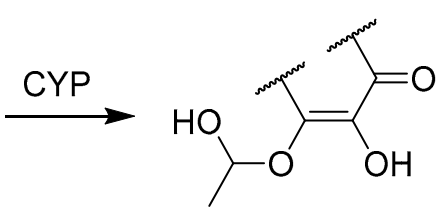

11

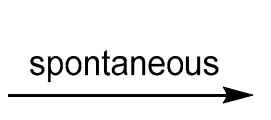

$\mathrm{HO}$<smiles>CC(=O)[CH+]C1=C(O)C(=O)C(C)C2CC1C2</smiles>

Figure 3. Mechanism for the CYP-mediated reversion of the 3-O-ethyl VC derivative to VC. Partial structures are shown. 
Thus, although the importance of stabilizing VC against oxidation and of improving its ability to penetrate into skin is well understood by pharmaceutical and cosmetic chemists, to date no chemical derivatives of $\mathbf{V C}$ have been reported that exhibit all those physiochemical properties (see above) and that also revert to VC rapidly and completely. The best approach to stabilizing VC against oxidation and improving its delivery into skin that has been reported to date is a formulation approach [2]. The formulation contains VC, vitamin $\mathrm{E}$ and ferulic acid at a $\mathrm{pH}$ of about 3 [8]. At $\mathrm{pHs}$ of about 3 the 3-OH group in VC is not substantially ionized, so it is not susceptible to the oxidation pathway shown in Figure 2. In addition, if the 3-OH group of VC is not ionized, VC is a much more lipid soluble (lipophilic) molecule and is thus able to cross the lipophilic barrier to penetration into skin (the stratum corneum) to a much greater extent. At pH 3 VC penetrates pig skin in vitro about four times better than it does at $\mathrm{pH} 5$ where $\mathrm{VC}$ is significantly ionized at the 3-OH group [2]. As attractive as such formulations are, the applications to skin of a neutral derivative of $\mathrm{VC}$ at $\mathrm{pH} 7$ exhibiting the physicochemical properties listed above, instead of a formulation at $\mathrm{pH} 3$, is very appealing.

Here we report that 3-O soft alkyl derivatives of VC and 5,6-isopropylidene-L-ascorbic acid, VCA, which had been previously synthesized $[9,10]$, exhibit physicochemical and biological properties that suggest that they would be ideal prodrugs of VC and VCA. The 3-O soft alkyl prodrugs mask the 3-OH group to stabilize the 1-one-2,3-diol-2-ene system to oxidation, they increase the lipid solubility of VC and VCA, and they revert to VC and to VCA chemically and enzymatically by the action of ubiquitous esterases-unlike the 3-O-ethyl derivative (10), they are prodrugs. In addition, the 3-O soft alkyl prodrug derivatives have been acylated in the 2-O position to further enhance the lipid solubilities of the prodrugs and to prevent potential rearrangements of the 3-O soft alkyl groups that could be mediated by the 2-OH group. The 2-O-acyl groups are also hydrolyzed by esterases.

Soft alkyl types of derivatives have been used for over 35 years to improve the physicochemical properties and the subsequent topical delivery of very polar drug molecules which contain acidic oxygen- or nitrogen-centered functional groups [7]. The design of soft alkyl derivatives takes advantage of the fact that hydrolysis of a functional group in the promoiety attached to a functional group in the parent molecule through a methylene (or vinylogous methylene) group gives an intermediate similar to $\mathbf{1 1}$ in Figure 3 which spontaneously reverts to the parent molecule and an aldehyde. A generic example of a soft alkyl derivative of a drug-XH (13) is shown in Figure 4 where $X, X^{\prime}$ and $X^{\prime \prime}$ can be $O$, $\mathrm{N}$ or $\mathrm{S}$, and $\mathrm{R}$ and $\mathrm{R}^{\prime}$ can be hydrogen, alkyl or aryl groups. In addition, $\mathrm{R}^{\prime}$ can be alkyloxy groups. Attack by a hydroxide anion or an esterase on the polarized $C\left(=X^{\prime \prime}\right)$ functional group leads to a cascade of rearrangements which ultimately result in the release of drug- $\mathrm{XH}, \mathrm{RCH}\left(=\mathrm{X}^{\prime}\right)$ and $\mathrm{R}^{\prime} \mathrm{C}\left(=\mathrm{X}^{\prime \prime}\right) \mathrm{OH}$. Most often, $X^{\prime}$ and $X^{\prime \prime}$ are oxygen so that the byproducts are an aldehyde and a carboxylic acid. Protonation of the intermediate $\mathbf{1 4}$ gives the same type of intermediate as $\mathbf{1 1}$ in Figure 3. Thus, soft alkyl prodrugs are stabilized forms of a hemiacetal such as $\mathbf{1 1}$.

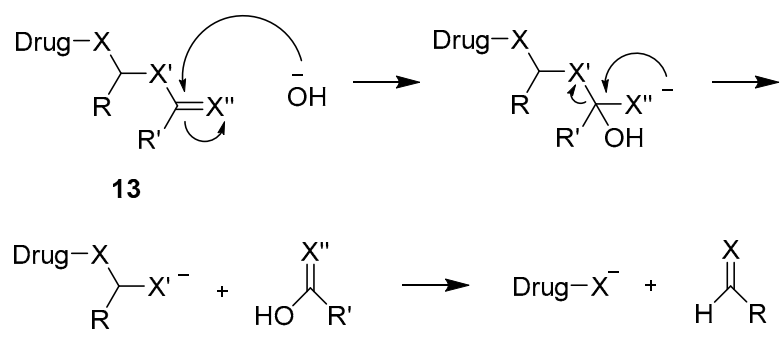

14

Figure 4. Mechanism for reversion of a soft alkyl derivative of an acidic functional group in a drug molecule.

The specific 3-O-soft alkyl derivatives, which are characterized here, are the 2-O-acyl-3-O-(1-acyloxyalkyl) derivatives of VCA, 15 (Figure 5) [9,10]. The regioselective preparation 
of 15 have been previously reported [10]. Here we report some preliminary results for (1) the water, $\mathrm{S}_{\mathrm{AQ}}$, and the 1-octanol, $\mathrm{S}_{\mathrm{OCT}}$, solubilities of a homologous series of $15,(2)$ the ability of a representative member of the homologous series of $\mathbf{1 5}$ (2-O-acetyl-3-O-acetyloxymethyl, 15a) to permeate a silicone membrane from its application in propylene glycol:water (PG:AQ), 30:70 [11,12], and (3) the ability of a different representative member of the homologous series of 15 [2-O-acetyl-3-O-(1-acetyloxyethyl), 15e] to inhibit oxidation in the cellular antioxidant assay (CAA) while maintaining low cytoxicity in the cell viability assay (CVA).

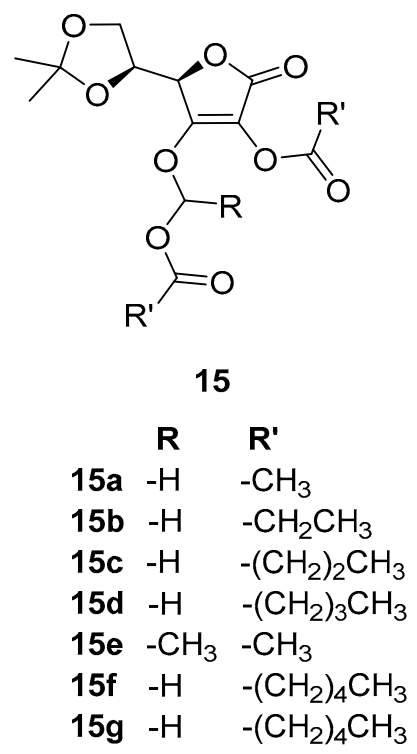

Figure 5. 2-O-acyl-3-O-(1-acyloxyalkyl) derivatives of VCA, 15a-g.

\section{Experimental}

Reagents and solvents used in this report were purchased from Sigma-Aldrich (St Louis, MO, USA), were of reagent grade and used without further purification. The Franz diffusion cells (surface area $4.9 \mathrm{~cm}^{2}$, receptor volume $20 \mathrm{~mL}$ ) were obtained from Crown Glass (Somerville, NJ, USA). Silicone membranes $(0.254 \mathrm{~mm})$ were obtained from Pillar Surgical (La Jolla, CA, USA). The solvents and the water bath used with the diffusion cells were obtained from Fisher Scientific (Pittsburg, PA, USA). The ${ }^{1} \mathrm{H}$ and ${ }^{13} \mathrm{C}-\mathrm{NMR}$ spectra were run on a Varian Mercury, $400 \mathrm{MHz}$, spectrometer. The ultraviolet (UV) spectra were run on a Shimadzu UV-2550 spectrophotometer. VCA was also purchased from Sigma-Aldrich or synthesized by a previously published method [13]. The synthesized VCA was identical with the purchased VCA by TLC, mp and ${ }^{1} \mathrm{H}-\mathrm{NMR}$.

\section{Methods}

\subsection{Synthesis}

Cleavage of the 5,6-isopropylidene group in 2-O-hexanoyl-3-O-hexanoyloxymethyl-5,6-isopropylidene-Lascorbic acid, 15f. 15f was synthesized according to a previously published procedure [9]. The 5,6-isopropylidene group was cleaved according to a previously published procedure [14]. To an acetonitrile $(10 \mathrm{~mL})$ solution containing $14 \mathrm{mg}(0.06 \mathrm{mmole})$ of antimony trichloride was added $15 \mathrm{f}$ ( $275 \mathrm{mg}, 0.6 \mathrm{mmole})$ followed by water $(10 \mu \mathrm{L}, 0.56 \mathrm{mmole})$. The reaction mixture was stirred at room temperature for $6 \mathrm{~h}$, quenched with $0.5 \mathrm{~mL}$ of saturated sodium bicarbonate and diluted with $50 \mathrm{~mL}$ of dichloromethane. The precipitate was removed by filtration and the filtrate was concentrated in vacuo without heating to give $180 \mathrm{mg}$ of the desired 2-O-hexanoyl-3-O-hexanoyloxymethyl-L-ascorbic acid as an oil in $75 \%$ yield, which was one component by TLC $\left(R_{f} 0.48\right.$, ethyl acetate:hexanes, $\left.1: 1\right)$ and which 
gave the correct elemental analysis. ${ }^{1} \mathrm{H}-\mathrm{NMR}\left(\mathrm{CDCl}_{3}\right) \delta 5.8\left(2 \mathrm{H}, \mathrm{dd},-\mathrm{O}-\mathrm{CH}_{2}-\mathrm{O}-\right), 4.91(1 \mathrm{H}, \mathrm{d}, 4-\mathrm{CH})$, $4.0(1 \mathrm{H}, \mathrm{dt}), 3.85(1 \mathrm{H}, \mathrm{dd}), 3.80(1 \mathrm{H}, \mathrm{dd}), 2.55\left(2 \mathrm{H}, \mathrm{t}, \mathrm{CH}_{2}-\mathrm{C}(=\mathrm{O})-\mathrm{O}\right), 2.35\left(2 \mathrm{H}, \mathrm{t}, \mathrm{CH}_{2}-\mathrm{C}(=\mathrm{O})-\mathrm{O}\right)$.

\subsection{Solubilities}

Direct solubilities were measured according to previously published procedures [15]. Briefly, excess prodrugs 15a-d, VC, VCA or VC 6-palmitate were suspended in 1-octanol, OCT, or water, AQ, and the suspensions were stirred for $1 \mathrm{~h}$ in the case of the prodrugs in $\mathrm{AQ}$ or for $24 \mathrm{~h}$ in the case of the prodrugs in OCT. Excess VC, VCA or VC 6-palmitate were suspended in OCT or water and stirred for $24 \mathrm{~h}$ before the suspensions were filtered. Excess VC, VCA and prodrug 15a were also suspended in propylene glycol (PG):water (AQ), 30:70, and stirred for $24 \mathrm{~h}$ before the suspensions were filtered. All of the suspensions were stirred at $23 \pm 1{ }^{\circ} \mathrm{C}$. All of the saturated solutions were diluted with $\mathrm{AQ}$ or acetonitrile (ACN) and the UV absorption of each solution was measured. The saturated concentration of each compound was determined using Beer's Law and the previously measured molar absorptivities $\left(\varepsilon, \mathrm{L} \cdot \mathrm{mol}^{-1}\right.$ or $\mathrm{M}^{-1}$ ) of each compound in $\mathrm{AQ}$ or $\mathrm{ACN}$ to give $\mathrm{S}_{\mathrm{OCT}}, \mathrm{S}_{\mathrm{AQ}}$ or $\mathrm{S}_{30: 70}$.

Indirect solubilities were also estimated by first measuring the partition coefficients of the molecules between OCT and AQ according to previously published procedures [15]. Briefly, the UV absorptions of the saturated solutions of the compounds, calculated from the UV absorptions of the samples diluted with AQ or ACN to keep absorption values between 0.2 and 2, in either OCT or $A Q$ were taken. Then, the saturated solutions were partitioned against the other solvent (OCT against $A Q$, or $A Q$ against OCT) and the UV absorptions of the initial saturated solutions (OCT or AQ, respectively) were measured again after separation of the two solvents and dilution of the OCT or AQ phases, respectively. The resulting partition coefficients were calculated as absorbances before $\left(A_{B}\right)$ and absorbances after $\left(\mathrm{A}_{\mathrm{A}}\right)$ multiplied by the inverse of the ratios of the volumes of the two solvents used $\left(\mathrm{V}_{\mathrm{OCT}}\right.$ or $\left.\mathrm{V}_{\mathrm{AQ}}\right)$. Thus, if OCT was the initial saturated solution:

$$
\mathrm{K}_{\mathrm{OCT}: \mathrm{AQ}}=\mathrm{A}_{\mathrm{A}} /\left(\mathrm{A}_{\mathrm{B}}-\mathrm{A}_{\mathrm{A}}\right) \times\left(\mathrm{V}_{\mathrm{AQ}} / \mathrm{V}_{\mathrm{OCT}}\right)
$$

When the initial saturated solution was $\mathrm{AQ}, \mathrm{K}_{\mathrm{AQ}}$ :OCT was obtained, from which $\mathrm{K}_{\mathrm{OCT}} \mathrm{AQ}$ could be calculated by taking the inverse of $\mathrm{K}_{\mathrm{AQ}: \mathrm{OCT}}$. Assuming that the solubility ratio (SR) and the partition coefficient are essentially equivalent $\left(\mathrm{SR}_{\mathrm{OCT}: \mathrm{AQ}}=\mathrm{K}_{\mathrm{OCT}: \mathrm{AQ}}\right)$, then estimated $\mathrm{S}_{\mathrm{AQ}}=\mathrm{S}_{\mathrm{OCT}} / \mathrm{K}_{\mathrm{OCT}: \mathrm{AQ}}$ or $\mathrm{S}_{\mathrm{OCT}}=\left(\mathrm{K}_{\mathrm{OCT}: \mathrm{AQ}}\right)\left(\mathrm{S}_{\mathrm{AQ}}\right)$.

\subsection{Diffusion Cell Experiments}

The diffusion cell experiments were run according to a previously described procedure using Franz diffusion cells maintained at $32{ }^{\circ} \mathrm{C}$ with a circulating water bath, silicone as the membrane and PG:AQ, 30:70, as the donor and the receptor phases [16]. Briefly, the donor suspensions were prepared by suspending $1.2 \mathrm{~g}$ of VC, $250 \mathrm{mg}$ of VCA or $60 \mathrm{mg}$ of 15a in $4 \mathrm{~mL}$ of PG:AQ, 30:70, for either $24 \mathrm{~h}$ for VC or $2 \mathrm{~h}$ for VCA or 15a with stirring at $23 \pm 1{ }^{\circ} \mathrm{C}$. An aliquot $(1.0 \mathrm{~mL})$ of each suspension was applied to the donor side of each of three diffusion cells $(n=3)$ and the donor phases were sealed with Parafilm. The donor phases remained as suspensions throughout the experiments. Samples were taken from the receptor phases every 10-12 $\mathrm{h}$ after application and the receptor phases were changed after each sampling. After sample acquisition, the donor phases of VC, VCA and 15a were always replaced with freshly prepared donor suspensions. After $4-5$ samples were taken, the donor phases were removed, the membrane surfaces were washed with $\mathrm{CH}_{3} \mathrm{OH}$ and the membranes were leached with $\mathrm{CH}_{3} \mathrm{OH}$ for $72 \mathrm{~h}$ to remove residual VC, VCA or 15a (or VCA from the hydrolysis of 15a) from the silicone membranes.

A second application $(1.0 \mathrm{~mL})$ of a suspension of $400 \mathrm{mg}$ of theophylline in $6 \mathrm{~mL}$ of PG was made to each membrane after the leaching period was complete. The second applications part of the experiment were run to determine if any damage to the integrity of the membranes had been caused by the first applications [17]. Samples of the receptor phases were taken every $24 \mathrm{~h}$ after the 
second application until 3 samples had been acquired. The receptor phases were changed after each sample acquisition.

The amounts of VC, VCA or 15a in the diffusion cells at each sampling time for the first applications and the amounts of theophylline for the second applications were determined from their UV absorption at their respective $\lambda_{\max }$ in PG:AQ, 30:70, using the molar extinction coefficients that had been previously measured. Flux values were calculated from the slopes of the plots of cumulative amounts versus time divided by the surface area of the membranes to give the maximum flux through a silicone membrane from PG:AQ, 30:70: $\mathrm{J}_{\mathrm{MP}}$ 30:70 in $\mu$ mole $\cdot \mathrm{cm}^{-2} \cdot \mathrm{h}^{-1}$. Steady state was taken as from 11 to $45 \mathrm{~h}$ for the first applications and from 24 to $72 \mathrm{~h}$ for the second applications. The second application fluxes were found to be within the standard deviation reported for the literature value for the maximum flux of theophylline through a silicone membrane from its suspension in propylene glycol (PG): $\log \mathrm{J}_{\mathrm{MPPG}}=-2.68+/-0.12 \mu$ mole $\cdot \mathrm{cm}^{-2} \cdot \mathrm{h}^{-1}$ [15]. No values for $\log \mathrm{J}_{\mathrm{MPPG}}$ different from $-2.68 \pm 0.12 \mu$ mole $\cdot \mathrm{cm}^{-2} \cdot \mathrm{h}^{-1}$ were observed.

\subsection{Cellular Antioxidant Activity (CAA) Assay and Cell Viability Analysis (CVA) Experiments}

The CAA assay and CVA experiments were each performed by Brunswick Labs (Southbough, MA, USA) under the supervision of Dr. Jin Ji using previously reported procedures $[18,19]$.

Briefly, the CAA assay was run using HaCaT cells instead of HepG2 cells as previously reported [20]. Triplicate wells containing the HaCaT cells were treated for $24 \mathrm{~h}$ with $100 \mu \mathrm{L}$ of 15e or quercetin in 16:84, PG:HBSS (Hanks' Balanced Salt Solution) plus $25 \mu \mathrm{M}$ DCFH-DA ( $2^{\prime}, 7^{\prime}$-dichlorofluorocin diacetate) in HBSS. Then $600 \mu \mathrm{M}$ ABAP (2,2'-azobis (2-amidinopropane) dihydrochloride) in $100 \mu \mathrm{L}$ of HBSS was added and the 96-well microplate was placed into a Fluoroskan Ascent FL plate-reader (ThermoLabsystems, Franklin, MA, USA) at $37^{\circ} \mathrm{C}$. Emission at $538 \mathrm{~nm}$ was measured with excitation at $485 \mathrm{~nm}$ every $5 \mathrm{~min}$ for $1 \mathrm{~h}$. Control wells contained cells treated with DCFH-DA and ABAP. After blank subtraction from the fluorescence readings, the area under the curve of fluorescence versus time was integrated to calculate the CAA value at each concentration as follows:

$$
\text { CAA unit }=100-\left(\int \mathrm{SA} / \int \mathrm{CA}\right) \times 100
$$

where $\int \mathrm{SA}$ is the integrated area under the sample fluorescence versus time curve and $\int \mathrm{CA}$ is the integrated area under the control fluorescence versus time curve. The median effective dose $\left(\mathrm{EC}_{50}\right)$ was determined from the plot of $\log \left(f_{a} / f_{u}\right)$ versus $\log$ dose, where $f_{a}$ is the fraction affected and $f_{u}$ is the fraction unaffected by the sample treatment at each concentration of $15 \mathbf{e}$ or quercetin. In each experiment quercetin was used as the standard and cellular antioxidant activity for 15e was expressed as micromoles of quercetin equivalents (QE) per 100 micromoles of $\mathbf{1 5 e}$.

Briefly, in the CVA analysis HaCaT cells were treated with a series of concentrations of 15e for $24 \mathrm{~h} \mathrm{[19]}$. The degree of cell viability was assessed by measuring the amount of cellular adenosine triphosphate (ATP) remaining after treatment with 15e, where ATP functions as a biomarker for metabolically active cells. The maximum concentration of 15e used to treat the cells that decreased the ATP bioluminescence absorbance by less than $10 \%$ was considered to be non-cytotoxic at that concentration.

\section{Results and Discussion}

\subsection{Synthesis}

The various 2-acyl-3-O-(1-acyloxyalkyl)-5, 6-L-ascorbic acid derivatives, 15, used in these experiments were synthesized by either Pathway A [9] or Pathway B [10], shown in Schemes 1 and 2 , respectively. 
major component
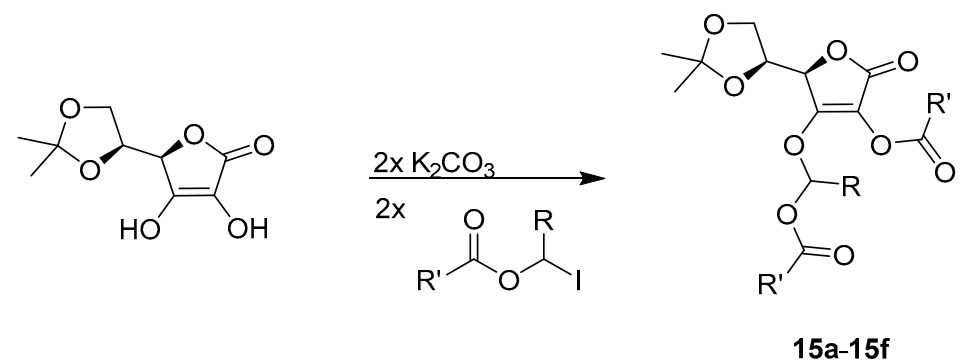

Scheme 1. Pathway A for the synthesis of 2-acyl-O-(1-acyloxyalkyl)-5,6-L-ascorbic acid derivatives, 15.<smiles>CC1(C)OCC([C@H]2OC(=O)C(O)=C2O)O1</smiles><smiles>[R]C(=O)Cl</smiles><smiles>[R]C(=O)OC1=C(O)[C@@H]([C@H]2COC(C)(C)O2)OC1=O</smiles><smiles>[R]C(=O)OC([R])I</smiles><smiles>[R]C(=O)OC1=C(OC([R])OC([R])=O)C(C2COC(C)(C)O2)OC1=O</smiles>

$15 \mathrm{e}$

Scheme 2. Pathway B for the synthesis of 2-acyl-O-(1-acyloxyalkyl)-5,6-L-ascorbic acid derivatives, 15.

The prodrugs 15a-e that are characterized here were all synthesized from the reaction of two equivalents of (1-acyloxyalkyl)-1-iodide with one equivalent of VCA in acetone using $\mathrm{K}_{2} \mathrm{CO}_{3}$ as base in a heterogeneous reaction (Scheme 1). These reactions gave a complex mixture of products from which the major components, 15a-e, were isolated, frequently in only low yield. Subsequently, a straight forward, two-step synthesis was developed that cleanly gave much better yields of $\mathbf{1 5}$ in which $\mathrm{R}^{\prime}$ at the 2-O and 3-O positions can be varied independently to give more diverse structures for 15 (Scheme 2). However, 15a-d were not resynthesized for use in the determination of their solubilities (Section 4.2) using the improved two-step process.

The cleavage of the 5,6-isopropylidene group from 15 to give a prodrug of VC, instead of VCA, had not been previously reported. Here we report that the 5,6-isopropylidene group of 2-O-hexanoyl-3-O-hexanoyloxymethyl-5,6-isopropylidene-L-ascorbic acid can be easily removed using a catalytic amount of antimony trichloride and one equivalent of water. The isolation of the product in good yield required only quenching the reaction with bicarbonate, filtering the resulting reaction mixture and concentrating the filtrate. Thus, the 2-O-acyl-3-O-(1-acyloxyalkyl) derivatives of L-ascorbic acid can be easily obtained and can serve as prodrugs of L-ascorbic acid, VC, itself in addition to the 2-O-acyl-3-O-(1-acyloxyalkyl)-5,6-isopropylidene derivatives of L-ascorbic acid serving as prodrugs of VCA. In either case the prodrugs protect the 1-one-2,3-diol-2-ene system from premature oxidation and impart increased lipophilicity to either VC or VCA to improve their delivery. Importantly, either VC or VCA express the full complement of the antioxidant properties of the 1-one-2,3-diol-2-ene system in VC.

\subsection{Solubilities}

The solubilities in 1-octanol and water ( $\mathrm{S}_{\mathrm{OCT}}$ and $\mathrm{S}_{\mathrm{AQ}}$, respectively) and the log partition coefficients between OCT and $\mathrm{AQ}\left(\log \mathrm{K}_{\mathrm{OCT}} \mathrm{AQ}\right)$ that were determined for 15a-e (Table 1) show that the data for the series is consistent from one member of the series to the next. In homologous series of prodrugs such as $\mathbf{1 5 a}-\mathbf{d}$, as $\mathrm{CH}_{2}$ groups are sequentially added to n-alkyl groups in the promoieties, the difference between the $\log \mathrm{K}_{\mathrm{OCT}: \mathrm{AQ}}$ of the first member of the series and the next member of the series remains a constant-methylene $\pi$ [15]. The value of methylene $\pi$ for $\log \mathrm{K}_{\mathrm{OCT}: \mathrm{AQ}}$ measurements 
is about $0.55 \log$ units. For the present homologous series of prodrugs $15 \mathbf{a}-\mathbf{d}$, the average of the difference between contiguous members of the series was $1.16+/-0.04 \log$ units. Since two $\mathrm{CH}_{2}$ groups were added to the prodrugs as $\mathrm{R}^{\prime}$ was increased by one $\mathrm{CH}_{2}$ group, the methylene $\pi$ value for the 15a-d series is half of $1.16 \log$ units: $0.58 \log$ units. This value is consistent with methylene $\pi$ values for other series of prodrugs [15]. Also as expected, as $\mathrm{CH}_{2}$ groups were added the $\mathrm{S}_{\mathrm{OCT}}$ and the $\log \mathrm{K}_{\mathrm{OCT}: \mathrm{AQ}}$ values increased and the $\mathrm{S}_{\mathrm{AQ}}$ values decreased [15].

Table 1. Molar extinction coefficients in water $\left(\varepsilon_{\mathrm{AQ}}\right)$ or in acetonitrile $\left(\varepsilon_{\mathrm{ACN}}\right)$, solubilities in water $\left(\mathrm{S}_{\mathrm{AQ}}\right)$ and in 1-octanol $\left(\mathrm{S}_{\mathrm{OCT}}\right)$ and $\log$ partition coefficients between 1-octanol and water $\left(\log \mathrm{K}_{\mathrm{OCT}} \mathrm{AQ}\right)$ for L-ascorbic acid derivatives.

\begin{tabular}{|c|c|c|c|c|c|c|c|}
\hline Compound & $\mathbf{R}$ & $\mathbf{R}^{\prime}$ & $\lambda_{\max }\left(\varepsilon_{\mathrm{AQ}}\right)^{\mathbf{a}, \mathbf{b}}$ & $\lambda_{\max }\left(\varepsilon_{\mathrm{ACN}}\right)^{\mathbf{a}, \mathrm{b}}$ & $S_{\text {OCT }}^{c}$ & $\mathrm{~S}_{\mathrm{AQ}}{ }^{\mathrm{c}}$ & $\log \mathrm{K}_{\mathrm{OCT}: \mathrm{AQ}}$ \\
\hline $15 a$ & $-\mathrm{H}$ & $-\mathrm{CH}_{3}$ & $224(10,775)$ & $217(11,012)$ & $35.8^{\mathrm{d}}$ & $36.5^{\mathrm{e}}$ & $-0.01^{\mathrm{e}}$ \\
\hline $15 b$ & $-\mathrm{H}$ & $-\mathrm{CH}_{2} \mathrm{CH}_{3}$ & $224(10,367)$ & $220(10,475)$ & $87.5^{\mathrm{d}}$ & $6.46^{\mathrm{e}}$ & $1.13^{\mathrm{e}}$ \\
\hline $15 \mathrm{c}$ & $-\mathrm{H}$ & $-\left(\mathrm{CH}_{2}\right)_{2} \mathrm{CH}_{3}$ & $224(11,712)$ & $220(12,327)$ & $437^{d}$ & $2.04^{\mathrm{e}}$ & $2.33^{\mathrm{e}}$ \\
\hline $15 d$ & $-\mathrm{H}$ & $-\left(\mathrm{CH}_{2}\right)_{3} \mathrm{CH}_{3}$ & $224(10,775)$ & $220(11,060)$ & $2387^{e}$ & $0.94^{\mathrm{f}}$ & $3.40^{\mathrm{e}}$ \\
\hline $15 e$ & $-\mathrm{CH}_{3}$ & $-\mathrm{CH}_{3}$ & $225(10,389)$ & $221(10,425)$ & $60.6^{\mathrm{g}}$ & $16.3^{\mathrm{e}}$ & $0.57^{\mathrm{h}}$ \\
\hline $15 f^{i}$ & $-\mathrm{H}$ & $-\left(\mathrm{CH}_{2}\right)_{4} \mathrm{CH}_{3}$ & ND & ND & ND & ND & ND \\
\hline $15 g^{i, j}$ & $-\mathrm{H}$ & $-\left(\mathrm{CH}_{2}\right)_{4} \mathrm{CH}_{3}$ & ND & ND & ND & ND & ND \\
\hline \multicolumn{2}{|c|}{ VC 6-palmitate } & & $244(9012)^{k}$ & $238(9374)$ & $57.8^{\mathrm{e}}$ & $0.008^{f}$ & $3.85^{\mathrm{e}}$ \\
\hline
\end{tabular}

${ }^{a}$ Wavelength in $\mathrm{nm} ;{ }^{\mathrm{b}}$ Molar extinction coefficients in $\mathrm{L} \cdot \mathrm{mole}^{-1}$ or M $^{-1} ;{ }^{\mathrm{c}}$ Concentrations in $\mathrm{mM} ;{ }^{\mathrm{d}}$ Calculated from the product of the measured partition coefficient between 1-octanol and water ( $\left.\mathrm{K}_{\mathrm{OCT}: \mathrm{AQ}}\right)$ and the measured $\mathrm{S}_{\mathrm{AQ}} ;{ }^{\mathrm{e}}$ Measured directly; ${ }^{\mathrm{f}}$ Calculated from the measured $\mathrm{S}_{\mathrm{OCT}}$ divided by the measured $\mathrm{K}_{\mathrm{OCT}: \mathrm{AQ}}$; ${ }^{\mathrm{g}}$ Calculated from the product of the estimated $\mathrm{K}_{\mathrm{OCT}: \mathrm{AQ}}$ and the measured $\mathrm{S}_{\mathrm{AQ}} ;{ }^{\mathrm{h}}$ Estimated from the average of the contribution of each $\mathrm{CH}_{2}$ group to the difference between $\log \mathrm{K}$ for contiguous members of a homologous series; ${ }^{i} \lambda_{\max }\left(\varepsilon_{\mathrm{AQ}}\right), \lambda_{\max }\left(\varepsilon_{\mathrm{ACN}}\right), \mathrm{S}_{\mathrm{OCT}}, \mathrm{S}_{\mathrm{AQ}}$ and $\log \mathrm{K}_{\mathrm{OCT}} \mathrm{AQ}$ were not measured; ${ }^{\mathrm{j}} \mathbf{1 5 g}$ is $\mathbf{1 5 f}$ with the acetonide removed; ${ }^{\mathrm{k}}$ Molar extinction coefficient in methanol.

For 15e, the $S_{A Q}$ value was measured directly. The log $K_{O C T: A Q}$ value for $15 e$ of 0.57 was estimated from the $\log \mathrm{K}_{\mathrm{OCT}} \mathrm{AQ}$ value of -0.01 for $15 \mathrm{a}$, which had been measured directly, and the methylene $\pi$ value of $0.58 \log$ units which has been calculated from the $\log \mathrm{K}_{\mathrm{OCT}} \mathrm{AQ}$ values for the $15 \mathrm{a}$ to $15 \mathrm{~d}$ series. Then the $\mathrm{S}_{\mathrm{OCT}}$ value for 15e was calculated from $\left(\mathrm{K}_{\mathrm{OCT}: \mathrm{AQ}}\right)\left(\mathrm{S}_{\mathrm{AQ}}\right)$ to give $60.6 \mathrm{mM}$. Both 15a and 15e exhibited a good balance of lipid and aqueous solubilities $\left(\mathrm{S}_{\mathrm{OCT}} / \mathrm{S}_{\mathrm{AQ}}=0.98\right.$ and 3.72, respectively) as well as being the two smaller molecules in the series [7]. Thus, they are both good candidates to increase the delivery of VCA.

\subsection{Diffusion Cell Results}

The diffusion cells were run in triplicate using propylene glycol:water (PG:AQ), 30:70, as the donor and receptor phases [11,12]. Silicone membranes were used as a surrogate for human skin. Because of its good balance between $\mathrm{S}_{\mathrm{OCT}}$ and $\mathrm{S}_{\mathrm{AQ}}, 15 \mathrm{a}$ was chosen to represent the series of prodrugs to determine the effectiveness of this type of prodrug. Suspensions of each compound (VC, VCA or 15a) were applied to maximize the thermodynamic activity of each compound in the vehicle and in the membrane.

As expected (Table 2), we found that no discernable VC was observed in the receptor phases of the cells to which VC had been applied. Also as expected, since VCA was about 4 times more soluble in the lipid 1-octanol than VC, a moderate flux of VCA was observed under the same conditions. Finally, the delivery of intact 15a was about 15 times more effective than the delivery of VCA by VCA. Thus, the delivery of molecules containing the transiently masked 1-one-2,3-diol-2-ene system is much more effective than the delivery of molecules in which that very polar system is not masked. 
Table 2. Molar extinction coefficients in propylene glycol:water (PG:AQ), 30:70 ( $\left.\varepsilon_{30: 70}\right)$, solubilities in 1-octanol $\left(\mathrm{S}_{\mathrm{OCT}}\right)$ and in water $\left(\mathrm{S}_{\mathrm{AQ}}\right)$ and maximum flux values through silicone membranes from PG:AQ, 30:70 (JMP 30:70) of VC, VCA and 15a.

\begin{tabular}{cccccc}
\hline Compound & $\mathbf{M W}$ & $\lambda_{\max }\left(\varepsilon_{\mathbf{3 0 : 7 0}}\right)^{\mathbf{a}, \mathbf{b}}$ & $\mathbf{S}_{\mathbf{O C T}}{ }^{\mathbf{c}}$ & $\mathbf{S}_{\mathbf{A Q}}{ }^{\mathbf{c}}$ & $\mathbf{J}_{\mathbf{M P} \mathbf{3 0 : 7 0}}{ }^{\mathbf{d}}$ \\
\hline VC & 176 & $258(8,855)$ & 4.93 & 1659 & $-\mathrm{e}$ \\
VCA & 216 & $266(11,823)$ & 19.7 & 228 & 0.0019 \\
15a & 330 & $224(11,473)$ & 35.8 & 36.5 & 0.028 \\
\hline
\end{tabular}

a Wavelength in $\mathrm{nm}{ }^{\mathrm{b}}$ Molar extinction coefficients in PG:AQ, 30:70, in: $\mathrm{L} \cdot$ mole $^{-1}$ or $\mathrm{M}^{-1}$; $^{\mathrm{c}}$ Concentration in $\mathrm{mM} ;{ }^{\mathrm{d}}$ Flux values in $\mu$ mole $\cdot \mathrm{cm}^{-2} \cdot \mathrm{h}^{-1} ;{ }^{\mathrm{e}}$ No flux observed.

\subsection{Cellular Antioxidant Activity (CAA) and Cell Viability Analysis (CVA)}

Although there are a wide variety of chemical antioxidant activity assays, many are not performed at physiological $\mathrm{pH}$ and none of them are capable of taking into account bioavailability, cellular uptake and metabolism of the antioxidant. In the case of prodrugs that are meant to function inside cells after they have been metabolized by hydrolysis, an assay that also measures activity based on the ability of the test molecule to cross a lipid biological membrane is essential. In the CAA assay using HepG2 cells [18], VC exhibits an $\mathrm{EC}_{50}$ value $(67.5 \mu \mathrm{M})$ that is about 10 times greater (10 times less potent) than the standard, quercetin. Usually, the results from the CAA assay are converted to $\mu$ mole quercetin equivalents $/ 100 \mu \mathrm{mol}$ of the tested antioxidant (QE) where the value for quercetin is set at $100 \mathrm{QE}$. In terms of QE values, VC only gave a value of $4 \mathrm{QE}$, making it 25 times less potent than quercetin by that criteria. In the CAA assay performed here using the HaCaT cell line (a spontaneous transformed aneuploid immortal keratinocyte cell line), which would be more appropriate for measuring topical antioxidant activity, VC only gave a value of about 2 QE [20].

In order to measure the CAA potency of the soft alkyl type of prodrugs, 15e was used as the representative of the series. The hydrolysis of $\mathbf{1 5 e}$ produces acetaldehyde, which is much less toxic than the formaldehyde produced from the hydrolysis of 15a. When 15e was tested in the CAA assay using $\mathrm{HaCaT}$ cells, the QE value was $62 \mu$ mole equivalents of quercetin $/ 100 \mu$ mole of 15e. Thus, 15e was about 30 times more potent than $\mathbf{V C}$ in the CAA assay, which requires the tested molecule to cross a biological membrane to express its activity. In this case, it also means that the prodrug hydrolyzed to the active VCA once it crossed the membrane into the cell: 15e was functioning as a prodrug.

The normal plasma concentration of VC is about $50 \mu \mathrm{M}$. When 15e was tested in the CVA assay using $\mathrm{HaCaT}$ cells, the maximum concentration of $\mathbf{1 5 e}$ that maintained or promoted cell viability was $920 \mu \mathrm{M}$. Thus, no toxicity for 15e was observed at a concentration that was 20 times greater than the normal concentration of VC in plasma.

\section{Conclusions}

A true prodrug of the highly polar 1-one-2,3-diol-2-ene set of connected functional groups in 5,6-isopropylidene-L-ascorbic acid (VCA) and L-ascorbic acid (VC) has been identified. 2-O-Acyl-3-O-(1-acyloxyalkyl) derivatives of VCA (15a-e) and VC (15g) have been regioselectively synthesized. The water and lipid solubilities $\left(\mathrm{S}_{\mathrm{AQ}}\right.$ and $\left.\mathrm{S}_{\mathrm{OCT}}\right)$ have been measured and several molecules in the series of prodrugs that exhibit the balanced lipid and aqueous solubilites necessary for improved delivery across biological membranes [7] have been identified. One representative of the series (15a) has been shown to enhance the delivery of $\mathbf{1 5 a}$ across a silicone membrane from propylene glycol:water, 30:70 by about 15 times compared to the delivery of VCA by VCA across the same membrane from the same vehicle. Another representative of the series (15e) has been shown to inhibit cellular oxidation about 30 times better than $\mathrm{VC}$ while at the same time maintaining low toxicity at a concentration 20 times greater than the normal concentration of VC in plasma. The soft alkyl type of prodrug of VC and its derivatives effectively cross HaCaT membranes and decrease cellular oxidation 
without causing decreased cell viability. They fill the need for molecules with these properties that had not been met before.

Acknowledgments: This research was not funded by any external sources. The work performed by Brunswick lab was paid for with personal funds. Jin Ji supervised the work done by Brunswick lab.

Author Contributions: Nikki A. Thiele performed the diffusion cell experiments and determined some of the solubility data. Jennifer McGowan developed the method for selectively cleaving the acetonide protecting group and determined some of the solubility data. Kenneth B. Sloan supervised the research and wrote the manuscript. All of the coauthors read and edited the manuscript and approved it.

Conflicts of Interest: The authors declare no conflict of interest.

\section{References}

1. Stamford, N.P.J. Stability, transdermal penetration, and cutaneous effects of ascorbic acid and its derivatives. J. Cosmet. Dermatol. 2012, 11, 310-317. [CrossRef] [PubMed]

2. Pinnell, S.R.; Yang, H.; Omar, M.; Riviere, N.M.; DeBuys, H.V.; Walker, L.C.; Wang, Y.; Levine, M. Topical L-ascorbic acid: Percutaneous absorption studies. Dermatol. Surg. 2001, 27, 137-142. [CrossRef] [PubMed]

3. Tojo, K.; Lee, A.C. Bioconversion of a provitamin to vitamins C and E in skin. J. Soc. Cosmet. Chem. 1987, 38, 333-339.

4. Gramlich, G.; Zhang, J.; Nau, W.M. Increased antioxidant reactivity of vitamin C at low $\mathrm{pH}$ in model membranes. J. Am. Chem. Soc. 2002, 124, 11252-11253. [CrossRef] [PubMed]

5. Budavari, S., Ed.; The Merck-Index-An Encyclopedia of Chemicals, Drugs, and Biological, 12th ed.; Merck and Co., Inc.: Whitehouse Station, NJ, USA, 1996; pp. 867-868.

6. Bors, W.; Buettner, G.R. The vitamin C radical and its reaction. In Vitamin C in Health and Disease; Packer, L., Fuchs, J., Eds.; Marcel Dekker: New York, NY, USA, 1997; Chapter 4; pp. 75-94.

7. Sloan, K.B. Functional group considerations in the development of prodrug approaches to solving drug delivery problems. In Prodrugs: Topical and Ocular Drug Delivery; Sloan, K.B., Ed.; Marcel Dekker, Inc.: New York, NY, USA, 1992; Chapter 2; pp. 17-116.

8. $\quad$ Lin, F.; Lin, J.; Gupta, R.D.; Tournas, J.A.; Burch, J.A.; Selin, M.A.; Monteiro-Riviere, N.A.; Grichnik, J.M.; Zielinski, J.; Pinnell, S.R. Ferulic acid stabilizes solutions of vitamins $\mathrm{C}$ and $\mathrm{E}$ and doubles its photo-protection of skin. J. Investig. Dermatol. 2005, 125, 826-832. [CrossRef] [PubMed]

9. McGowan, J.; Thiele, N.; Sloan, K.B. Prodrugs of vitamin C: The reaction of 1-acyloxyalkyl-1-iodides with vitamin C 5,6-acetonide. Tetrahedron Lett. 2015, 56, 5441-5444. [CrossRef]

10. Prybylski, J.; Thiele, N.; Sloan, K.B. Regioselective synthesis of 2-O-acyl-3-O-(1-acyloxyalkyl) prodrugs of 5,6-isopropylidene-L-ascorbic acid. Tetrahedron Lett. 2016, 57, 1619-1621. [CrossRef]

11. Sloan, K.B.; Devarajan-Ketha, H.; Synovec, J.; Majumdar, S. Fit of fluxes of sunscreens and other compounds from propylene glycol:water (30:70) through human skin and silicone membrane to the Roberts-Sloan equation: The effect of polar vehicle (or water) solubility. J. Cosmet. Sci. 2013, 64, 181-192. [PubMed]

12. Hagedorn-Lewke, U.; Lippold, B. Absorption of sunscreens and other compounds through human skin in vivo: Derivation of a method to predict fluxes. Pharm. Res. 1995, 12, 1354-1360. [CrossRef]

13. Jung, M.E.; Shaw, T.J. Total synthesis of (R)-glycerol acetonide and the antiepileptic and hypotensive drug (-)- $\gamma$-amino- $\beta$-hydroxybutyric acid (GABOB): Use of vitamin $C$ as a chiral starting material. J. Am. Chem. Soc. 1980, 102, 6304-6311. [CrossRef]

14. Wu, Q.; Chen, W.; Wang, Y.; Qu, Y.; Zhang, Q. Mild, efficient and highly selective hydrolysis of acetonides with antimony luchloirde. Lett. Org. Chem. 2006, 3, 271-274.

15. Beall, H.D.; Getz, J.J.; Sloan, K.B. The estimation of relative water solubility for prodrugs that are unstable in water. Int. J. Pharm. 1993, 93, 37-47. [CrossRef]

16. Wasdo, S.; Juntunen, J.; Devarajan, H.; Murray, T.; Nichels, K.; Singh, S.; Shanks, J.; Ulmer, K.; Sloan, K.B. Modeling of flux through silicone membranes from water. Eur. J. Pharm. Sci. 2008, 34, 321-332. [CrossRef] [PubMed]

17. Sloan, K.B.; Koch, S.A.M.; Siver, K.G.; Flowers, F.P. The use of solubility parameters of drug and vehicles to predict flux. J. Invertig. Dermatol. 1986, 75, 744-749.

18. Wolfe, K.L.; Lin, R.H. Cellular antioxidant activity (CAA) assay for assessing antioxidants, foods, and dietary supplements. J. Agric. Food Chem. 2007, 55, 8896-8907. [CrossRef] [PubMed] 
19. Crouch, S.P.M.; Kozlowski, R.; Slater, K.J.; Fletcher, J. The use of ATP bioluminescence as a measure of cell proliferation and cytotoxicity. J. Immunol. Methods 1993, 160, 81-88. [CrossRef]

20. Bender, C.; Grazeano, S.; Zimmerman, B.F.; Weidlich, H.H. Antioxidant potential of aqueous plant extracts assessed by the cellular antioxidant activity assay. Am. J. Biol. Life Sci. 2014, 2, 72-79.

(C) 2016 by the authors; licensee MDPI, Basel, Switzerland. This article is an open access article distributed under the terms and conditions of the Creative Commons Attribution (CC-BY) license (http:/ / creativecommons.org/licenses/by/4.0/). 